\title{
Diagnose por subtração de macronutrientes em mudas de tomate para processamento industrial
}

O objetivo do estudo foi identificar e descrever os sintomas visuais em mudas de tomate para processamento industrial, decorrentes da carência individual de macronutrientes e avaliar atributos biométricos nessa fase, bem como seu estado nutricional. O experimento foi conduzido em estufa agrícola, em blocos casualizados, com oito tratamentos e quatro repetições. Os tratamentos foram: solução nutritiva completa; soluções com omissão individual dos nutrientes $\mathrm{N}$, $\mathrm{P}$, $\mathrm{K}, \mathrm{Ca}, \mathrm{Mg}$ e S; e solução apenas com água deionizada. As sementes foram semeadas em bandejas com substrato e posteriormente transplantadas para bandejas com espuma fenólica. Diariamente aplicavam-se as soluções nutritivas. Durante 30 dias foram realizadas análise descritivas e registros da evolução dos sintomas de deficiência nutricional. Aos 30 dias após a semeadura, foram obtidas a leituras do Índice Relativo de Clorofila, altura, diâmetro do caule e o número de folhas das mudas dos híbridos (N901 e H9553) de tomate industrial e a parte aérea das mudas foram armazenadas para a determinação da matéria seca. As omissões promoveram alterações morfológicas, caracterizadas por sintomas visuais de deficiência nutricional, sendo a omissão de $\mathrm{N}$, água deionizada e Ca os primeiros a apresentar os sinais de carência. As deficiências dos nutrientes $\mathrm{N}$ e Ca foram as mais limitantes para o desenvolvimento das mudas de tomate industrial. A carência de $\mathrm{N}$ e de $\mathrm{Mg}$ foram as que mais afetaram o IRC. O clorofilômetro pode ser utilizado para avaliar o estado nutricional das mudas de tomate industrial.

Palavras-chave: Elemento Faltante; Índice Relativo de Clorofila; Solanum lycopersicum L.; Viveiro Comercial.

\section{Diagnose by subtracting of macronutrients in seedlings of tomato processing}

\begin{abstract}
The objective of the study was to identify and describe the visual symptoms in seedlings of tomato processing, stemming from lack of macronutrients and evaluate biometric attributes that stage, as well as their nutritional status. The experiment was conducted in an agricultural greenhouse, in randomized complete block, with eight treatments and four replications. The treatments were: complete nutrient solution; solutions with individual omission of nutrients $\mathrm{N}, \mathrm{P}, \mathrm{K}$, $\mathrm{Ca}$, $\mathrm{Mg}$ and $\mathrm{S}$; and solution only with deionized water. Held sowing in trays with substrates for later transplanting for phenolic foam. Nutritional solutions were applied daily. For 30 days of experiment was realized descriptive analysis and records of the evolution of nutritional deficiency symptoms. At 30 days after sowing, were obtained readings of the relative index of chlorophyll, height, stem diameter and the number of leaves of the seedlings of the hybrids (N901 and H9553) of industrial tomato and the aerial part of the seedlings were stored for the determination of dry matter. The omissions promoted morphological changes, characterized by visual symptoms of nutritional deficiency, with the omission of $\mathrm{N}$, deionized water and Ca being the first to show signs of deficiency. The deficiencies of nutrients $\mathrm{N}$ and Ca were the most limiting for the development of industrial tomato seedlings. The lack of $\mathrm{N}$ and Mg were the most affected the IRC. The chlorophyll meter can be used to assess the nutritional status of seedlings of tomato industrial.
\end{abstract}

Keywords: Missing Element; Relative Index of Chlorophyll; Solanum lycopersicum L.; Commercial nursery.

Topic: Proteção de Plantas e Fitotecnia

Reviewed anonymously in the process of blind peer.
Received: 02/08/2020

Approved: 19/09/2020
Yoná Serpa Mascarenhas (iD

Instituto Federal do Piauí, Brasil

http://lattes.cnpq.br/9499442555783589

http://orcid.org/0000-0002-8721-5367

yona.mascarenhas@ifpi.edu.br

Abadia dos Reis Nascimento (it)

Universidade Federal de Goiás, Brasil

http://lattes.cnpq.br/6270103344297514

http://orcid.org/0000-0003-3952-5878

nascimentoufg@gmail.com

\section{Vladia Correchel (D)}

Universidade Federal de Goiás, Brasil

http://lattes.cnpq.br/4781536691286837

http://orcid.org/0000-0001-7109-2588

vladiacorrechel@hotmail.com

\author{
Eli Regina Barboza de Souza \\ Universidade Federal de Goiás, Brasil \\ http://lattes.cnpq.br/7641431808466123 \\ http://orcid.org/0000-0001-6225-6122 \\ eliregina1@gmail.com \\ Gelson Goulart da Silva Lima \\ Universidade Federal de Goiás, Brasil \\ http://lattes.cnpq.br/9022326100414581 \\ vivatigo@grupovivati.com.br
}

\section{Referencing this:}

MASCARENHAS, Y. S.; NASCIMENTO, A. R.; CORRECHEL, V.; SOUZA, E. R. B.; LIMA, G. G. S.. Diagnose por subtração de macronutrientes em mudas de tomate para processamento industrial. Revista Ibero Americana de Ciências Ambientais, v.11, n.5, p.99-112, 2020. DOI: http://doi.org/10.6008/CBPC2179-6858.2020.005.0011 


\section{INTRODUÇÃO}

A cultura do tomate (Solanum lycopersicum) é uma das mais expressivas no cenário agrícola mundial, constituindo importante produto para o comércio in natura e indústria de extratos, destacando-se por sua produção, industrialização e valor econômico (DOMINGOS, 2009). A produção de tomate destinado à indústria representa 37\% do que é produzido no Brasil, enquadrando o País entre os dez maiores produtores tomate para processamento do mundo (WPTC, 2020).

O sucesso do cultivo de tomate, assim como das demais hortaliças, depende da formação de mudas de alta qualidade, o que torna o cultivo de hortaliças mais competitivo, com o aumento de produtividade e diminuição dos riscos de produção. $\mathrm{O}$ uso de mudas no plantio diminui a perda de sementes, o ciclo da cultura no campo e permite uma maior uniformidade da produção (MIN AMI, 1995). Das áreas cultivadas com tomate para processamento industrial, 100\% utilizam mudas no plantio para viabilizar a atividade (EMBRAPA, 2006).

A produção em larga escala de mudas tem motivado os produtores a adotar novas técnicas, métodos e equipamentos (OVIEDO et al., 2012). Produtores de mudas de tomate industrial têm enfrentado diversos desafios, aprimorando e buscando novas tecnologias, principalmente no exterior, e realizando suas próprias pesquisas (NASCIMENTO et al., 2013). Neste cenário, estudos sobre nutrição mineral são essenciais para o ajustamento do programa de fertirrigação buscando maximizar a eficiência de produção de mudas de tomate por meio de uma nutrição equilibrada.

A carência de cada elemento considerado essencial para o crescimento das plantas desencadeia fenômenos bioquímicos dentro das plantas, os quais são externados por sintomas típicos (EPSTEIN et al., 2005). O diagnóstico de problemas nutricionais, mediante a observação de sintomas, representa grande importância tanto na fase de viveiro quanto na de campo, pois permite a tomada de decisões rápidas para a correção das deficiências, além de fornecer suporte para possíveis alterações no programa das soluções nutritivas para serem fertirrigadas. Os estudos voltados para caracterização dos sintomas de deficiências nutricionais de macronutrientes, bem como dos nutrientes mais limitantes são referentes à planta adulta, não tendo sido encontrados trabalhos com foco para o cultivo de mudas do tomateiro destinados a produção industrial.

O objetivo do estudo foi identificar e descrever os sintomas visuais de deficiência nutricional, bem como avaliar as características biométricas e o estado nutricional na fase de muda, decorrentes do efeito da omissão individual dos macronutrientes em dois híbridos (N901 e H9553) de tomate para processamento industrial.

\section{MATERIAIS E MÉTODOS}

O estudo foi conduzido em estufa agrícola, de novembro a dezembro de 2013 , no viveiro comercial Vivati-Abadia de Goiás, localizado no município de Abadia de Goiás, GO, (16 45'26" S, 49 $26^{\circ} 15^{\prime \prime}$ W e 898 metros de altitude média). O clima, de acordo Koppen, é do tipo "Aw", com precipitação média de $1.575 \mathrm{~mm}$. 
A estufa agrícola era germinada com pedilúvio, antecâmaras e telados com malha máxima de 0,239 $\mathrm{mm}$, conforme estabelecido pelo Ministério da Agricultura. Leituras diárias da temperatura e umidade relativa do ar foram feitas a partir de dados obtidos na estação meteorológica WatchDog. As temperaturas máximas no interior da estufa variaram de 32 a $45{ }^{\circ} \mathrm{C}$ e as mínimas de 18 a $22{ }^{\circ} \mathrm{C}$. A umidade relativa variou entre 48 e $71 \%$.

O delineamento experimental foi em blocos casualizados, com oito tratamentos e quatro repetições. Os tratamentos foram: Testemunhas - solução completa/controle, solução apenas com água deionizada, solução nutritiva com omissão individual de $\mathrm{N}, \mathrm{P}, \mathrm{K}, \mathrm{Ca}, \mathrm{Mg}$ e S. Cada parcela foi representada por uma bandeja com 20 mudas de tomate industrial, sendo 10 mudas do híbrido Heinz (H9553) e 10 do híbrido Nunhems (N901).

As sementes dos híbridos de tomate industrial foram adquiridas do Viveiro Vale Do Tietê - Grupo Vivati, e da empresa Nunhems/Bayer CropScience Brasil. Foram semeadas em bandejas de polietileno com 450 células, preenchidas com substrato a base de fibra de coco - (Golden mix, tipo 11) e cobertas com vermiculita. Para manter a temperatura e umidade constante as bandejas foram mantidas embaladas em filme de polietileno (Stretch) e lona plástica escura até a emergência das sementes. Em seguida foram levadas para estufa agrícola.

Doze dias após semeio (DAS) e com primeiro par de folhas bem definido, com $2 \mathrm{~cm}$, mas não totalmente desenvolvida e com, aproximadamente, $5 \mathrm{~cm}$ de altura, as plântulas foram selecionadas por tamanho similar, retiradas do substrato, lavadas com água corrente e deionizadas, aparando o sistema radicular e, em seguida, transplantadas para espuma fenólica acondicionada em recipiente plástico (copos descartáveis) com capacidade de $50 \mathrm{ml}$ contendo água deionizada até a superfície da espuma. As placas de espuma fenólica foram previamente submetidas à lavagem com água corrente e depois com água deionizada, para eliminação dos resíduos ácidos resultantes do processo de fabricação. Por um período de 72 horas de aclimatação permaneceram em um ambiente coberto (galpão), depois encaminhadas para estufa agrícola sob tela de $50 \%$ de sombreamento, e iniciou-se a aplicação dos tratamentos com $50 \%$ da força iônica da solução nutritiva (adaptação). Após uma semana retirou-se a tela de sombreamento (Figura 1).

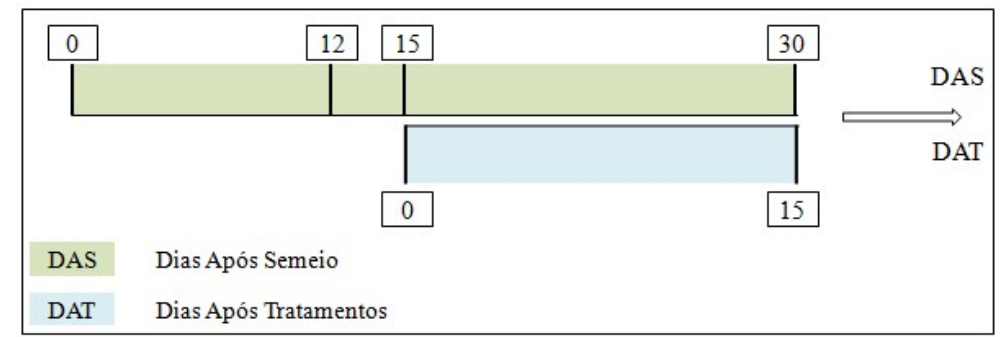

Figura 1: Ciclo das mudas de tomate industrial e a correspondência entre dias após semeio (DAS) e dias após aplicação dos tratamentos (DAT). Goiânia, UFG, 2013.

Decorrido o período de três dias, adaptação, as plântulas passaram a receber $80 \%$ da concentração da solução durante uma semana para, então, estarem aptas a receber 100\% (carga total) até o final do experimento. Renovavam-se diariamente as soluções, para evitar a formação de lodo e possível salinização das mudas. Em dias de alta evapotranspiração foram necessárias reposições, realizada com água deionizada. 
Foram feitas substituições das mudas mortas até uma semana após o transplantio.

As soluções nutritivas foram preparadas a partir da solução completa proposta por Hoagland et al. (1950), adaptada para cultura do tomate, que apresentava a seguinte concentração de nutrientes: (mg L'${ }^{-1}$ : 202,42 de N; 61,32 de P; 232,20 de K; 158,68 de Ca; 47,64 de Mg; 63,14 de S; 0,54 de B; 0,06 de Cu; 2,20 de Fe; 0,38 de Mn; 0,08 de Mo e 0,26 de Zn. Para compor os tratamentos, suprimia-se o macronutriente desejado da solução nutritiva, deixando os demais nutrientes nas mesmas concentrações encontradas na solução completa. Inicialmente preparou-se uma solução estoque ou de uso, utilizando reagentes puros diluídos em água deionizada. Depois utilizavam-se alíquotas para o preparo da solução nutritiva (tratamentos) conforme Tabela 1.

Tabela 1: Composição química das soluções nutritivas, em $\mathrm{ml} \mathrm{L}^{-1}$, utilizadas durante a condução do experimento de omissão de nutrientes em mudas de tomate para processamento industrial. Goiânia, UFG, 2013.

\begin{tabular}{|c|c|c|c|c|c|c|c|c|}
\hline \multirow{2}{*}{ Solução estoque } & \multicolumn{8}{|c|}{ Tratamentos } \\
\hline & Completo & $-N$ & $-P$ & $-K$ & $-\mathrm{Ca}$ & $-M g$ & $-S$ & $\mathrm{H}_{2} \mathrm{OD}^{1}$ \\
\hline & \multicolumn{8}{|c|}{ Macronutrientes $\left(\mathrm{mol} \mathrm{L}^{-1}\right)$} \\
\hline $\mathrm{KNO}_{3}$ & - & - & 6 & - & 6 & 6 & 6 & - \\
\hline $\mathrm{Ca}\left(\mathrm{NO}_{3}\right)_{2} .4 \mathrm{H}_{2} \mathrm{O}$ & - & - & 4 & 4 & & 4 & 4 & - \\
\hline$\left(\mathrm{NH}_{4}\right)_{2} \mathrm{HPO}_{4}$ & - & - & - & 2 & 2 & 2 & 2 & - \\
\hline $\mathrm{MgSO}_{4} \cdot 7 \mathrm{H}_{2} \mathrm{O}$ & - & 2 & 2 & 2 & 2 & - & - & - \\
\hline $\mathrm{NH}_{4} \mathrm{NO}_{3}$ & - & - & - & 3 & 3 & - & - & - \\
\hline $\mathrm{CaSO}_{4}-2 \mathrm{H}_{2} \mathrm{O}^{*}$ & - & 200 & - & - & - & - & - & - \\
\hline $\mathrm{NaNO}_{3}$ & - & - & - & - & 2 & - & - & - \\
\hline $\mathrm{K}_{2} \mathrm{H} \mathrm{PO}_{4}$ & - & 2 & - & - & - & - & - & - \\
\hline $\mathrm{K}_{2} \mathrm{SO}_{4} * *$ & - & 4 & - & - & - & - & - & - \\
\hline$\left(\mathrm{NH}_{4}\right)_{2} \mathrm{SO}_{4}$ & - & - & 1 & - & - & - & - & - \\
\hline $\mathrm{MgCl}_{2}-6 \mathrm{H}_{2} \mathrm{O}$ & - & - & - & - & - & - & 2 & - \\
\hline $\mathrm{Na}_{2} \mathrm{SO}_{4}$ & - & - & - & - & - & 2 & - & - \\
\hline $\mathrm{CaCl}_{2} 2 \mathrm{H}_{2} \mathrm{O}$ & - & 2 & - & - & - & - & - & - \\
\hline \multicolumn{9}{|c|}{ Micronutrientes (mmol L-1) } \\
\hline $\mathrm{H}_{3} \mathrm{BO}_{3} * * *$ & 2 & 2 & 2 & 2 & 2 & 2 & 2 & - \\
\hline $\mathrm{CuSO}_{4} \cdot 5 \mathrm{H}_{2} \mathrm{O} * * * *$ & 2 & 2 & 2 & 2 & 2 & 2 & 2 & - \\
\hline $\mathrm{H}_{2} \mathrm{MoO}_{4} * * * *$ & 2 & 2 & 2 & 2 & 2 & 2 & 2 & - \\
\hline $\mathrm{ZnSO}_{4} .7 \mathrm{H}_{2} \mathrm{O} * * * * *$ & 2 & 2 & 2 & 2 & 2 & 2 & 2 & \\
\hline $\mathrm{MnSO}_{4} \cdot \mathrm{H}_{2} \mathrm{O}^{* * * * *}$ & 2 & 2 & 2 & 2 & 2 & 2 & 2 & - \\
\hline EDTA Férrico & 4 & 4 & 4 & 4 & 4 & 4 & 4 & - \\
\hline
\end{tabular}

Em cada solução nutritiva (tratamento) foi feita a leitura da condutividade elétrica (CE), em mS cm${ }^{-1}$, e do $\mathrm{pH}$, com equipamento Combo portátil. $\mathrm{O}$ pH de cada solução era ajustado e corrigido periodicamente, mantendo-o na faixa de 5,5 a 6,0 com auxílio de soluções de $\mathrm{HCl} \mathrm{0,1} \mathrm{mol} \mathrm{L}^{-1}$ e $\mathrm{NaOH}$, respectivamente. A condutividade era mantida abaixo de $2,0 \mathrm{mS} \mathrm{cm}^{-1}$. A evolução dos sintomas de deficiência nutricional dos macronutrientes foi descrita e fotografada diariamente a partir do semeio até 30 DAS, período em que as mudas estão aptas a irem para o campo.

Aos 30 DAS foram efetuadas leituras do Indice Relativo de Clorofila (IRC), medições de altura e diâmetro do caule e contabilizado o número de folhas totalmente expandida dos híbridos de tomate industrial. Para o IRC as leituras foram mensuradas nas folhas mais novas e completamente expandidas, utilizando-se o clorofilômetro portátil ClorofiLOG ${ }^{\circ} 1030$ (FAA, 2008). A altura das mudas foi medida, em centímetros, usando uma régua graduada, a partir do substrato até a folha mais nova totalmente expandida. O diâmetro do caule foi medido com auxílio de um paquímetro digital $150 \mathrm{~mm}$ Tools Club, a 1,0 cm acima da 
superfície do substrato (espuma fenólica).

Depois, as mudas foram separadas em raízes e parte aérea, obtendo-se a massa da matéria fresca. Em seguida, as folhas foram acondicionadas, juntamente com o caule e ramos, em sacos de papel Kraft, secos em estufa com circulação de ar forçada a 65ํㅡ, até peso constante para determinação do peso da matéria seca da parte aérea (MSPA).

O material vegetal seco foi macerado em almofariz com pistilo de porcelana e submetido à digestão nitroperclórica para determinar os teores totais de $\mathrm{P}$, por redução do fosfomolibdato; $\mathrm{S}$, por turbidimetria do sulfato; K, por fotometria de emissão de chama; $\mathrm{Ca}$ e Mg, por espectrofotometria de absorção atômica; e N total, pelo método Kjeldahl (MALAVOLTA et al., 1997). Os dados foram submetidos às análises de variância e comparação de médias, sendo realizada por meio do teste Scott-Knott ao nível de $5 \%$ de probabilidade aplicando o programa computacional ASSISTAT (SILVA et al., 2009).

\section{RESULTADOS E DISCUSSÃO}

Os sintomas de deficiência visual apareceram na seguinte ordem: água deionizada, N, Ca, e as deficiências de $\mathrm{P}, \mathrm{K}, \mathrm{Mg}$ e $\mathrm{S}$ que apareceram concomitantes, aos 10 dias após a aplicação dos tratamentos. No tratamento com solução completa/controle notou-se ausência de alterações morfológicas, enquanto, no tratamento apenas com água deionizada, ou seja, completa ausência de nutrientes, ocorreu morte prematura das mudas (Figura 2).
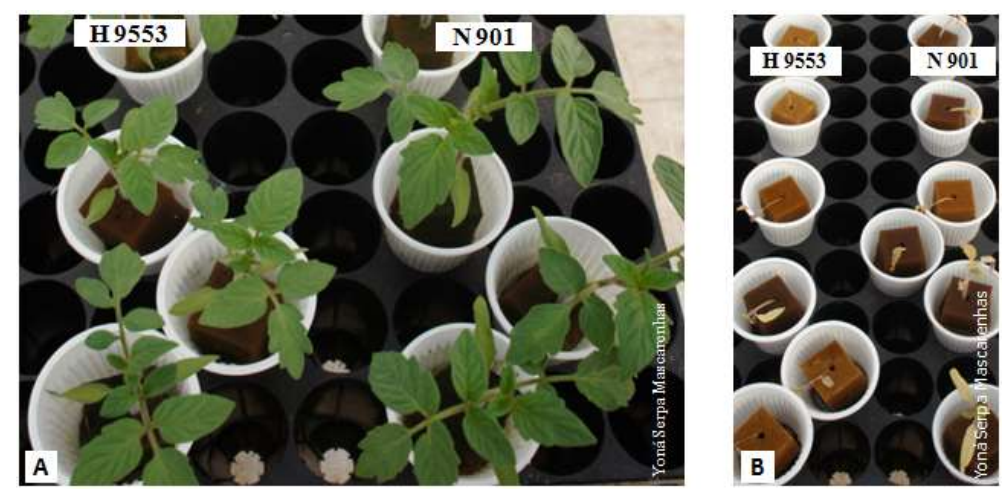

Figura 2: Mudas de tomate cultivadas em solução nutritiva completa $(A)$ e em água deionizada $\left(\mathrm{H}_{2} \mathrm{OD}\right)(B)$.

O sintoma de deficiência de $\mathrm{N}$ apareceu aos 4 dias após a aplicação dos tratamentos. A deficiência reduziu o crescimento das mudas de tomate quando comparado ao tratamento completo. As plântulas mostraram-se desnutridas, com os cotilédones completamente amarelados, crescimento retardado, caules pouco lignificados (pouca firmeza), com emissão de um par de folíolos em alguns indivíduos. Doze dias após início das aplicações ainda foi possível encontrar plântulas vivas, com caules extremamente frágeis e a base abaxial dos cotilédones com aspecto rosado, ocorrendo à morte das plântulas em seguida (Figura 3). Esses resultados concordam com os reportados por Maia (2012) em plantas de tomate do grupo cereja híbrido Sindy. 


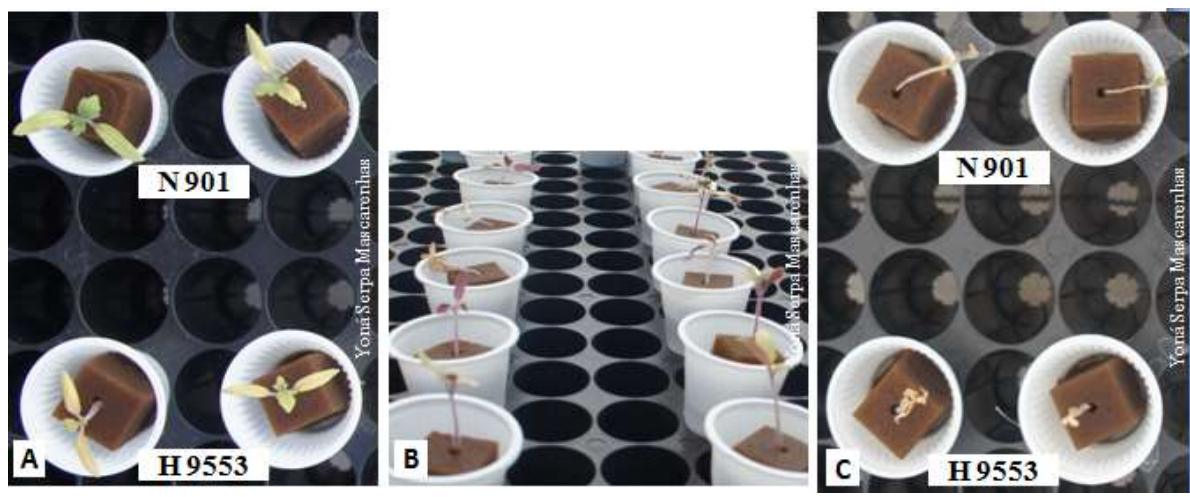

Figura 3: Sintomas de deficiência de N em mudas de tomate, híbridos N901 e H9553, aos 4 (A),12(B) e 14(C) dias após aplicação do tratamento. Goiânia, UFG, 2013.

De acordo com Taiz et al. (2009), a deficiência de N é caracterizada pela baixa taxa de crescimento, plantas pequenas, folhas de tamanho reduzido, morte prematura das folhas mais velhas, raízes sem ramificações, colapso dos cloroplastos, folhas cloróticas com necroses no estágio mais avançado da deficiência. Segundo Malavolta et al. (1997), o N além de fazer parte da estrutura de aminoácidos, proteínas, bases nitrogenadas, ácidos nucléicos, enzimas, coenzimas, vitaminas, pigmentos e produtos secundários, participa de processos como absorção iônica, fotossíntese, respiração, multiplicação e diferenciação celular. Assim, sua ausência na solução não permitiu o desenvolvimento das plântulas.

Após 10 dias de aplicação dos tratamentos, as plantas mantidas sob omissão de $P$ iniciaram os primeiros sintomas visuais de deficiência nutricional. Observou-se uma intensa cor arroxeada na parte abaxial dos folíolos, consequência do acúmulo de antocianina (Figura 1A). De acordo Malavolta et al. (1997) em plantas sob deficiência de $\mathrm{P}$ pode-se observar coloração verde-escura nas folhas mais velhas e, em algumas espécies, colorações avermelhadas e arroxeadas em consequência da acumulação de antocianina.
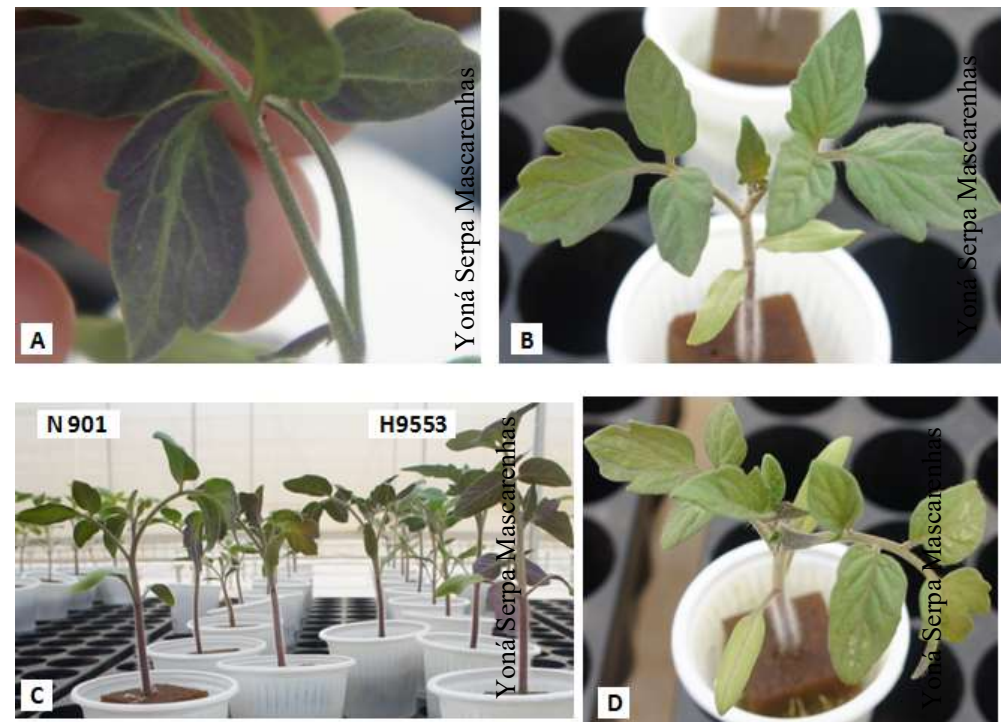

Figura 4: Sintomas de deficiência P em mudas de tomate, híbridos N901 e H9553, aos 10 (A), 12 (B e C) e 15 (D) dias após aplicação do tratamento. Goiânia, UFG, 2013.

Com a progressão da carência de P os folíolos mais velhos passaram a ter uma coloração verde opaco, sem brilho e nervuras roxo-claras. Houve acentuada redução no crescimento das plântulas, apresentando caules finos e levemente endurecidos em relação ao controle. O número de folhas e folíolos diminuiu e a cor 
verde opaco passou-a a verde marrom com alguns pontos necrosados (Figura 4). Entre as importantes funções exercidas pelo P na planta, o relevante papel na síntese de proteínas determina que sua carência se reflita no menor crescimento vegetal (MALAVOLTA, 2006), e com a deficiência prolongada de P pode levar ao surgimento de manchas necróticas marrom escuras nas folhas velhas e lesões necróticas nas margens das folhas (BERGMANN, 1992). Maia (2012) observou que a omissão de P na solução nutritiva não comprometeu o número de folhas em tomateiro do grupo cereja híbrido Sindy.

Os sintomas de deficiência de $\mathrm{K}$ começaram a ser observados aos 10 dias após a aplicação dos tratamentos, caracterizados pelo emborcamento dos folíolos (aspectos de guarda-chuva) e coloração amarelada nas bordas. Posteriormente, verificou-se pequenas pontuações cloróticas entre as nervuras dos folíolos mais velhos e emborcamento mais acentuado. As bordas amareladas e os pontos cloróticos evoluíram para lesões necróticas (aspecto queimado), progredindo-se das margens para o centro do limbo foliar. Em estágio avançado, as folhas que surgiam, apresentavam-se com uma coloração verde intensa e encarquilhadas. A omissão de $\mathrm{K}$ levou a um menor crescimento das mudas de tomate em comparação ao tratamento completo (Figura 5). Em plantas de tomateiro a deficiência de $\mathrm{K}$ retarda o crescimento, provoca afilamento de folhas novas e as velhas apresentam amarelecimento das bordas que vão se tornando amarronzadas e, em seguida, se necrosam (EMBRAPA, 2006).

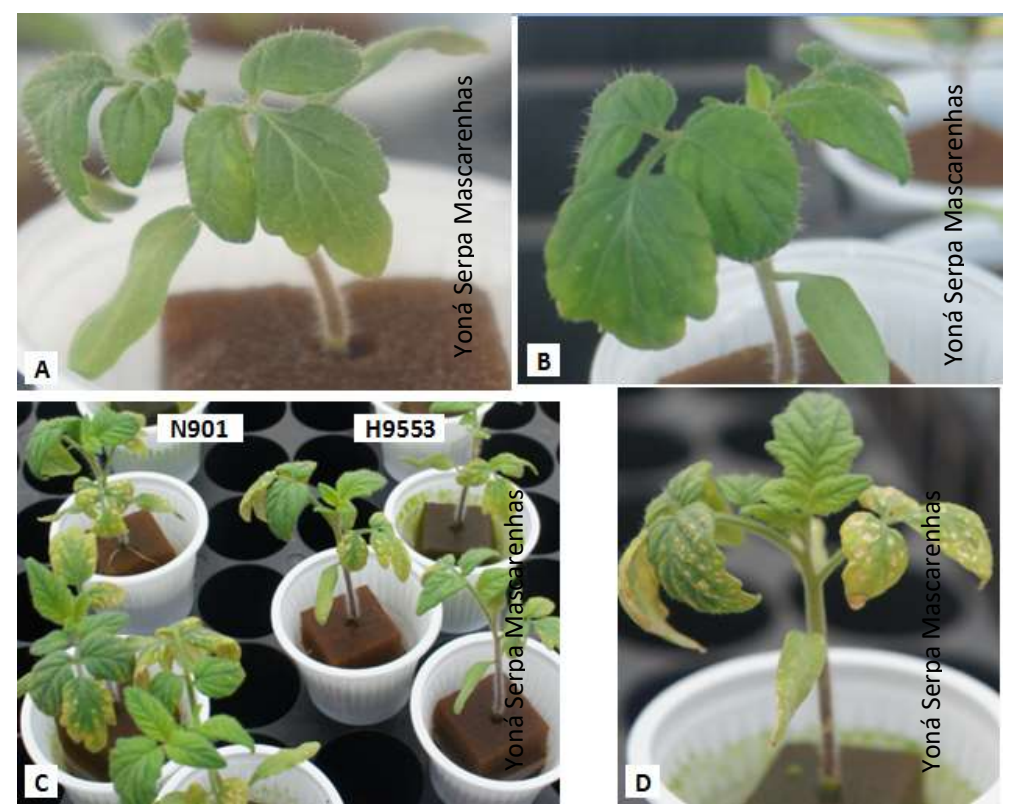

Figura 5: Sintomas de deficiência K em mudas de tomate, híbridos N901 e H9553, aos 10 (A), 11 (B), 13 (C) e 15 (D) dias após aplicação do tratamento. Goiânia, UFG, 2013.

Os sintomas identificados coincidiram com os descritos em plantas de beterraba (ALVES et al., 2008) e em plantas de pimenta longa descritos por Viégas et al. (2013). Em ambos estudos foram observadas a ocorrência de clorose ao longo das bordas das folhas mais velhas, expandindo-se em direção à nervura central e com a progressão da deficiência toda a lâmina foliar ficou clorótica e com necrose nas bordas e ápices das folhas. Epstein et al. (2005) relataram que em plantas com deficiência de K, os compostos nitrogenados solúveis, inclusive as aminas putrescinas e agmatina, muitas vezes, se acumulam, sendo esta última, provavelmente, responsável pelas manchas necróticas que aparecem nas folhas deficientes nesse 
nutriente.

Com a omissão de $\mathrm{Ca}$, inicialmente, observou manchas brancas nos folíolos mais novos do primeiro par de folhas das mudas, aos 6 dias após aplicação dos tratamentos. Com o avanço da deficiência, as manchas brancas tornaram-se levemente escurecidas e os folíolos deformados com bordas enrijecidas voltadas para cima. As folhas apresentaram uma coloração verde amarelada e com aspecto coriáceo (grosso), além de reduzido número e tamanho dos folíolos. Na região abaxial alguns folíolos apresentaram coloração avermelhada ou levemente arroxeada. A omissão de Ca foi a segunda mais severa, comprometendo o desenvolvimento das mudas, quando comparada ao controle, culminando com a morte apical aos 9 dias após aplicação dos tratamentos (Figura 6).

Bastos et al. (2013) relataram que a deficiência de Ca no tomateiro é caracterizada por necrose nas pontas e margens dos folíolos (folhas novas). Conforme Taiz et al. (2009), as plantas com deficiência de Ca apresentam uma redução no crescimento meristemático, observada primeiramente na região do crescimento apical e nas folhas mais novas, que se tornam deformadas e cloróticas e nos estágios mais avançados ocorre necrose das margens das folhas e os tecidos tornam-se "moles", devido à dissolução da parede celular.
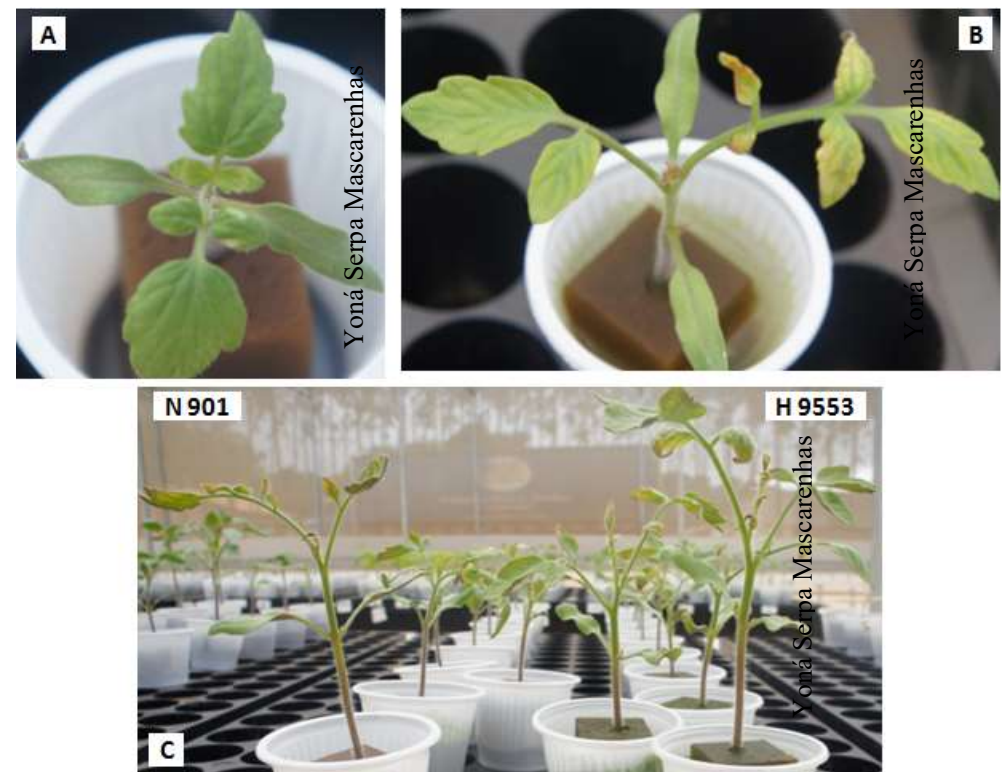

Figura 6: Sintomas de deficiência de Ca em mudas de tomate, híbridos N901 e H9553, aos 6 (A), 9 (B) e 15 (C) dias após aplicação dos tratamentos. Goiânia, UFG, 2013.

A deficiência de $\mathrm{Mg}$ foi caracterizada pela coloração verde claro e amarelecimento das pontas e margens das folhas mais velhas, inicialmente, que evoluíram para o amarelecimento total. Os ramos e folhas apresentaram uma textura macia e pouco enrijecidos com perceptível curvamento para baixo (formato de concha). Os ramos e caules exibiram uma coloração verde claro e as partes abaxiais dos folíolos apresentaram concentração de antocianina, expressa por uma cor levemente avermelhada. Com a severidade da deficiência surgiram manchas brancas entre as nervuras das folhas (Figura 7). Os primeiros sintomas ficaram visíveis aos 10 dias após a omissão do elemento na solução. Bastos et al. (2013) estudando deficiência nutricional em plantas adultas de tomateiro, verificou um formato de concha, mas com tendência de 
curvarem-se para cima, em plantas com deficiência em $\mathrm{Mg}$, diferente do presente estudo.

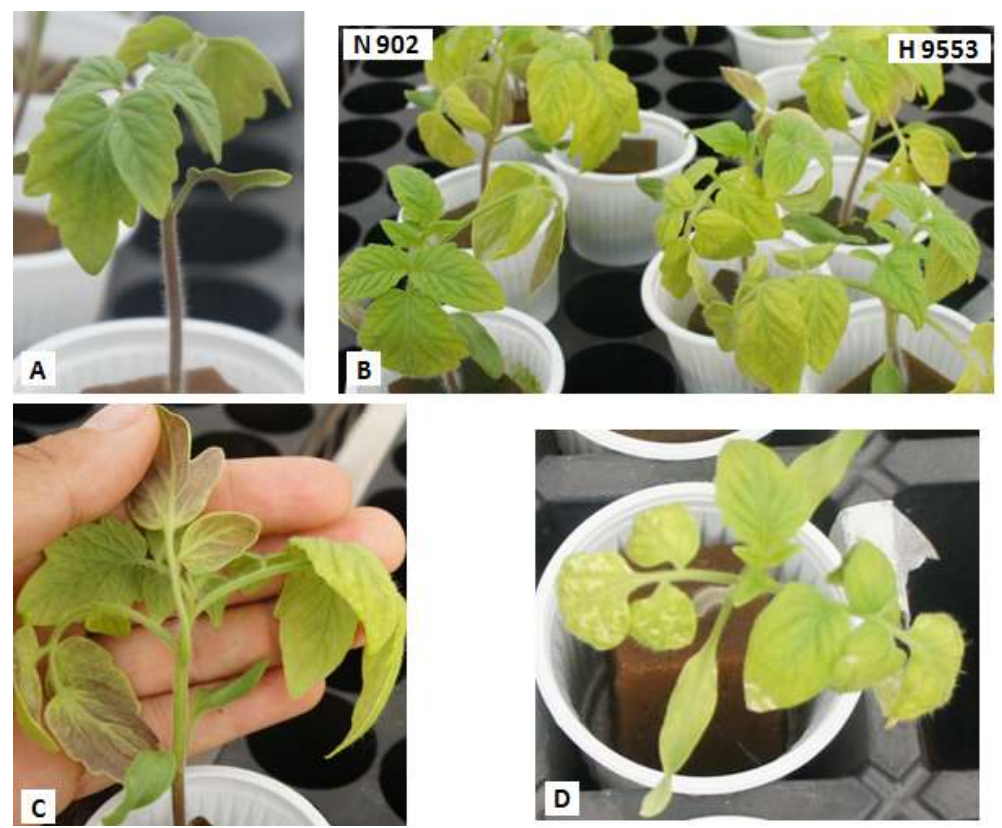

Figura 7: Sintomas de deficiência de Mg em mudas de tomate, híbridos N901 e H9553, aos 10 (A), 13 (B) e 15 (C e D) dias após aplicação dos tratamentos. Goiânia, UFG, 2013.

A deficiência de $\mathrm{Mg}$ é bastante comum em plantações de tomate e se caracteriza por uma descoloração das margens dos folíolos mais velhos, que progride em direção à área internerval, permanecendo as nervuras verdes. Quando a deficiência é mais severa, as áreas amarelas tornam-se escuras e posteriormente necrosadas (EMBRAPA, 2006). Estes sintomas, também, foram observados por Maia (2012) ao estudar omissão de Mg em tomate do tipo cereja híbrido Sindy. Segundo Taiz et al. (2009), a clorose entre as nervuras ocorre porque a clorofila nos feixes vasculares permaneceu inalterada por períodos mais longos que a clorofila nas células entre os feixes.
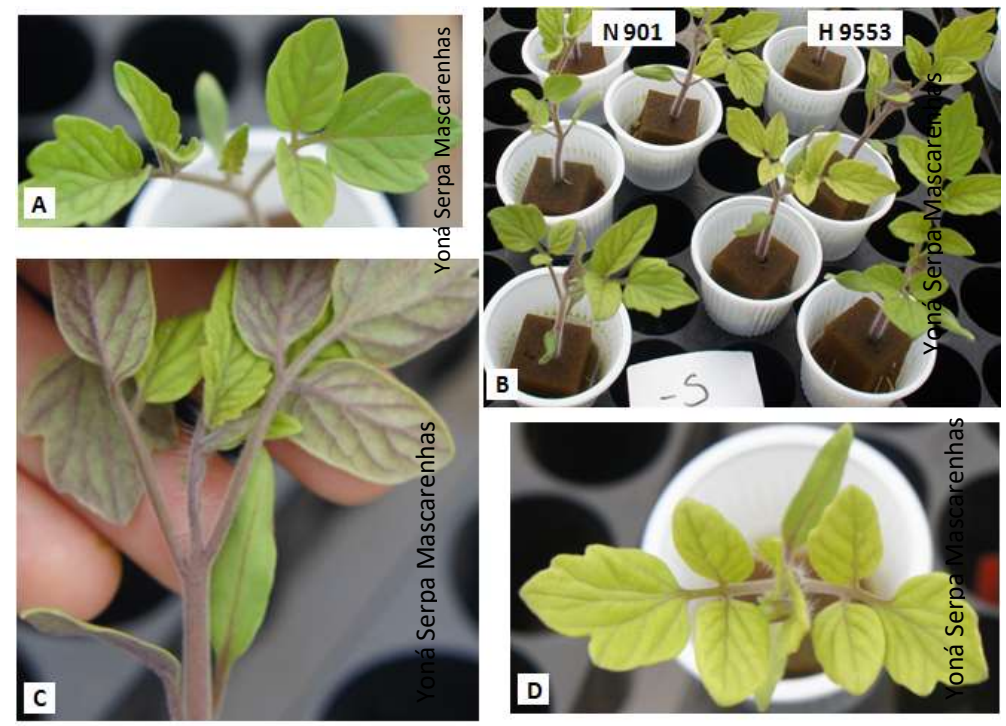

Figura 8: Sintomas de deficiência S em mudas de tomate, híbridos N901 e H9553, aos 10 (A), 14 (B), 14 (C) e 15 (D) dias após aplicação dos tratamentos. Goiânia, UFG, 2013.

Quando se omitiu o S, ocorreu uma descoloração gradativa do verde das folhas, passando a verdeamarelada, verde pálida, iniciando do centro das folhas para as margens, observada a partir dos 10 dias de 
omissão do nutriente. As folhas apresentaram uma arquitetura ereta, apontadas para cima em relação ao caule. As nervuras e os caules exibiram uma cor roxa, que se intensificou com a evolução da carência de $S$, devido ao provável acúmulo de antocianinas. A ausência de S levou a uma diminuição do número e tamanho das folhas e folíolos, além de provocar um achatamento destes e uma diminuição do diâmetro dos caules em relação ao controle. A cor verde-amarelada progrediu para uma clorose intensa e uniforme das mudas, resultando em folhas completamente amareladas (Figura 8).

Os resultados observados no presente estudo corroboram com os descritos por Epstein et al. (2005) que descreveram que plantas com deficiência de $\mathrm{S}$ os sintomas se manifestam com clorose e espigamento das folhas e redução no crescimento. Hewitt (1983) destaca que a deficiência de S em plantas reduz, principalmente, o tamanho das folhas, a concentração de clorofila e dos pigmentos vermelhos ou purpúreos.

As características biométricas altura das mudas, diâmetro do caule, número de folhas e matéria seca da parte aérea, foram limitadas, estatisticamente, pela omissão da maioria dos nutrientes, quando comparadas ao tratamento completo (Tabela 2). As limitações dessas características foram mais marcantes quando se omitiu $\mathrm{N}$ e Ca em relação ao tratamento completo.

Tabela 2: Médias de altura das mudas, diâmetro do caule (DC), número de folhas (NF), matéria seca da parte aérea (MSPA) e Índice Relativo de Clorofila (IRC) de mudas de tomate industrial, híbridos (N901 e H9553) aos 30 dias após semeadura sob omissão de nutrientes. Goiânia, UFG, 2013.

\begin{tabular}{llllll}
\hline- & Altura (cm) & DC (mm) & NF & MSPA (g) & IRC \\
\hline Cultivar (C) & - & - & - & - & - \\
\hline N901 & $5,14 \mathrm{a}$ & $1,85 \mathrm{a}$ & $4,14 \mathrm{a}$ & $0,36 \mathrm{a}$ & $26,00 \mathrm{a}$ \\
H9553 & $4,69 \mathrm{a}$ & $1,76 \mathrm{a}$ & $3,79 \mathrm{a}$ & $0,35 \mathrm{a}$ & $25,34 \mathrm{a}$ \\
\hline Teste F & $2,36^{\mathrm{ns}}$ & $0,94^{\mathrm{ns}}$ & $0,33^{\mathrm{ns}}$ & $0,43^{\mathrm{ns}}$ & $0,10^{\mathrm{ns}}$ \\
\hline \multicolumn{1}{c}{ Soluções (S) } & - & - & - & - & - \\
\hline Completa & $8,49 \mathrm{a}$ & $3,06 \mathrm{a}$ & $4,17 \mathrm{a}$ & $0,85 \mathrm{a}$ & $40,97 \mathrm{a}$ \\
$-\mathrm{N}$ & $1,54 \mathrm{c}$ & $0,48 \mathrm{~d}$ & $0,34 \mathrm{e}$ & $0,02 \mathrm{f}$ & $8,82 \mathrm{c}$ \\
$-\mathrm{P}$ & $6,07 \mathrm{~b}$ & $2,51 \mathrm{~b}$ & $3,00 \mathrm{~b}$ & $0,35 \mathrm{~d}$ & $42,88 \mathrm{a}$ \\
$-\mathrm{K}$ & $5,78 \mathrm{~b}$ & $1,89 \mathrm{c}$ & $3,12 \mathrm{~b}$ & $0,36 \mathrm{~d}$ & $36,35 \mathrm{a}$ \\
$-\mathrm{Ca}$ & $4,69 \mathrm{~b}$ & $1,69 \mathrm{c}$ & $2,02 \mathrm{~d}$ & $0,21 \mathrm{e}$ & $28,31 \mathrm{~b}$ \\
$-\mathrm{Mg}$ & $6,00 \mathrm{~b}$ & $2,05 \mathrm{c}$ & $3,75 \mathrm{a}$ & $0,59 \mathrm{~b}$ & $20,73 \mathrm{~b}$ \\
$-\mathrm{S}$ & $6,00 \mathrm{~b}$ & $2,62 \mathrm{~b}$ & $2,62 \mathrm{c}$ & $0,47 \mathrm{c}$ & $27,31 \mathrm{~b}$ \\
$\mathrm{H}_{2} \mathrm{O}$ D & $0,75 \mathrm{c}$ & $0,20 \mathrm{~d}$ & $0,00 \mathrm{e}$ & $0,00 \mathrm{f}$ & $0,00 \mathrm{~d}$ \\
\hline Teste F & $38,77^{* *}$ & $52,37^{* *}$ & $94,36^{* *}$ & $55,74^{* *}$ & $26,77^{* *}$ \\
\hline Teste F (CxS) & $0,31^{\mathrm{ns}}$ & $0,24 \mathrm{~ns}^{\mathrm{ns}}$ & $0,33^{\mathrm{ns}}$ & $0,38^{\mathrm{ns}}$ & $0,10^{* *}$ \\
\hline CV (\%) & 23,68 & 21,74 & 18,51 & 30,18 & 32,41 \\
\hline
\end{tabular}

${ }^{\text {ns }}$ Não significativo ( $\left.p>=.05\right)$.

** significativo ao nível de $1 \%$ de probabilidade $(p<.01)$.

Médias seguidas pela mesma letra na vertical não diferem significativamente ao nível de $5 \%$ de probabilidade, pelo teste Scott-nott.

$\mathrm{H}_{2} \mathrm{O} \mathrm{D}$, Água deionizada.

A restrição de $N$ foi a que mais limitou as características fitotécnicas estudadas. Raij (1991) afirma que o elemento, além de participar da composição da molécula de clorofila, participa também da reação de síntese proteica. A inibição desta síntese reduz o processo de divisão celular (MALAVOLTA et al., 1997), e, consequentemente, afeta o crescimento da planta. Como observado na tabela 2, a ausência do nitrogênio não diferiu estatisticamente do tratamento com água deioniza, apesar da presença dos demais nutrientes a ausência do nitrogênio foi suficiente para a não sobrevivência das mudas de tomate industrial. Mostrandose como o nutriente mais importante para a nutrição das mudas, sendo o que deve ser manejo mais 
cautelosamente na fertirrigação.

O Ca é essencial para manter a integridade estrutural e funcional das membranas e da parede celular com a falta de $\mathrm{Ca}$, os tecidos meristemáticos jovens, apicais e laterais, ficam cloróticos, necróticos e deformados (MALAVOLTA, 2006). E para que ocorra o alongamento celular, e consequentemente o desenvolvimento das plantas, é necessário afrouxamento das paredes celulares, que é induzido por auxina, hormônio regulado pelo cálcio, e realocação do Ca nas cadeias pécticas (CUNHA et al., 2009), assim, a deficiência de Ca resulta na redução da área foliar e no crescimento da planta. A ausência de Ca afetou, em aproximadamente, $45 \%$ da altura das mudas, $45 \%$ do diâmetro do caule, $52 \%$ do número de folhas e em $75 \%$ da produção da matéria seca das mudas em relação à solução controle.

A altura das mudas apresentou redução com a aplicação dos tratamentos de omissão na seguinte ordem: $\mathrm{H}_{2} \mathrm{OD}=\mathrm{N}>\mathrm{Ca}>\mathrm{K}=\mathrm{Mg}=\mathrm{S}=\mathrm{P}>$ completa. Para o diâmetro a ordem de restrição foi: $\mathrm{H}_{2} \mathrm{OD}=\mathrm{N}>\mathrm{Ca}$ $=\mathrm{K}=\mathrm{Mg}>\mathrm{P}=\mathrm{S}>$ completa e para a massa seca: $\mathrm{H}_{2} \mathrm{OD}=\mathrm{N}>\mathrm{Ca}>\mathrm{P}=\mathrm{K}>\mathrm{S}>\mathrm{Mg}>$ completa. A ordem de redução do número de folhas foi $\mathrm{N}=\mathrm{H}_{2} \mathrm{OD}>\mathrm{Ca}>\mathrm{S}>\mathrm{P}=\mathrm{K}>\mathrm{Mg}=$ completa (Tabela 2). Apenas o tratamento sob omissão de $\mathrm{Mg}$ não provocou redução no número de folhas em relação ao tratamento completo. Em tomateiro tipo cereja, a ausência de Mg também não provocou diminuição no número de folhas (MAIA, 2012). Em relação aos efeitos de interação entre os tratamentos solução nutritiva com omissão de nutrientes e cultivares, constatou-se a não interação entre estes fatores. Não houve efeito diferenciado exercido pelo fator solução nutritiva sob as diferentes cultivares (Tabela 2).

Verificou-se maior valor médio do IRC nos tratamentos em que ocorreram alterações morfológicas em menor intensidade, principalmente na mudança de pigmentação. A ordem dos nutrientes que mais limitaram a clorofila foram $\mathrm{H}_{2} \mathrm{O} \mathrm{D}>\mathrm{N}>\mathrm{Mg}=\mathrm{S}=\mathrm{Ca}>\mathrm{K}=\mathrm{P}=$ completa (Tabela 2). A clorofila é um pigmento, que reflete a cor verde nas plantas, que está relacionado com o potencial da atividade fotossintética, bem como o estado nutricional das plantas, geralmente, está associado com a quantidade e qualidade de clorofila (ZOTARELLI et al., 2002). Dessa forma, as plântulas que expressaram menor teor de clorofila, foram àquelas cultivadas em soluções nutritivas com ausência de nutrientes ligados diretamente a esta molécula e/ou aos processos fotossintéticos e de desenvolvimento da área foliar, sendo eles $\mathrm{N}, \mathrm{Mg}, \mathrm{S}$ e Ca. Para o IRC a omissão de P e K não diferiu estatisticamente do tratamento com solução completa.

A supressão de $\mathrm{N}$ e de $\mathrm{Mg}$ foram as que mais afetaram o IRC (Tabela 2). Nas plântulas cultivadas com omissão de N houve uma redução acentuada de $82 \%$ do IRC, ajustando-se a afirmativa de Raij (1991) de que o elemento participa da composição da molécula de clorofila. Com a omissão de Mg obteve-se uma redução de $58 \%$ no IRC. Como o Mg é o elemento central da molécula de clorofila (MALAVOLTA, 2006) é aceitável que a deficiência do nutriente acarrete tal redução. A redução do IRC decorrente da falta de $S$ alcançou $45 \%$, sendo o terceiro macronutriente mais limitante para o IRC. A insuficiência de $\mathrm{S}$ desencadeia inúmeros distúrbios metabólicos, pois este nutriente faz parte do composto da coenzima $A$, que é o ponto de convergência do metabolismo degradativo de carboidratos, aminoácidos e ácidos graxos (TAIZ et al., 2009). Segundo Furlani (2004) a ausência de S ocasiona menor teor de clorofila nas folhas. Com a ausência do Ca na solução nutritiva, as mudas obtiveram um reduzido desenvolvimento da área foliar (Figura 6), cerca de 43\% 
do IRC das plantas controle (Tabela 2).

A atividade fotossintética, o conteúdo de proteínas solúveis de nitrogênio $(\mathrm{N})$ e de outros macros existentes nas folhas são variáveis e podem ser correlacionados com o conteúdo de clorofila no tecido foliar (RAMOS et al., 2013). No presente estudo, ocorreu oscilação na intensidade de coloração verde das mudas, decorrente da subtração individual dos nutrientes na solução nutritiva, manejo que afetou estatisticamente o conteúdo de clorofila na folha (Tabela 2). A omissão dos nutrientes, quando comparada ao tratamento completo, causou redução acentuada no teor daquele que foi omitido, na parte aérea das mudas dos híbridos de tomate industrial (Tabela 3).

Tabela 3: Teor de macronutrientes $\left(\mathrm{g} \mathrm{kg}^{-1}\right)$ na parte aérea das mudas de tomate industrial, híbridos: N901 e H9553, aos 30 dias após semeadura, sob omissão de nutrientes. Goiânia, UFG, 2013.

\begin{tabular}{|c|c|c|c|c|c|c|c|c|c|c|c|c|}
\hline \multirow{2}{*}{ Tratamentos } & \multicolumn{2}{|l|}{$\mathbf{N}$} & \multicolumn{2}{|l|}{$\mathbf{P}$} & \multicolumn{2}{|l|}{ K } & \multicolumn{2}{|l|}{$\mathrm{Ca}$} & \multicolumn{2}{|l|}{ Mg } & \multicolumn{2}{|l|}{$\mathbf{S}$} \\
\hline & N901 & H9553 & N901 & H9553 & N901 & H9553 & N901 & H9553 & N901 & H9553 & N901 & H9553 \\
\hline Completo & 44,0 & 44,2 & 11,9 & 17,4 & 13,4 & 16,0 & 27,0 & 24,0 & 4,0 & 4,0 & 3,4 & 3,9 \\
\hline$-N$ & 0,0 & 0,0 & 0,0 & 0,0 & 0,0 & 0,0 & 0,0 & 0,0 & 0,0 & 0,0 & 0,0 & 0,0 \\
\hline$-P$ & 44,5 & 45,4 & 4,5 & 4,7 & 26,0 & 19,6 & 29,0 & 25,0 & 4,0 & 4,0 & 5,9 & 7,0 \\
\hline$-\mathrm{K}$ & 56,3 & 52,9 & 22,4 & 21,3 & 9,2 & 9,4 & 40,0 & 16,0 & 4,0 & 4,0 & 5,8 & 5,8 \\
\hline - Ca & 41,4 & 37,5 & 23,5 & 19,5 & 14,2 & 20,6 & 4,0 & 8,0 & 4,0 & 3,0 & 6,5 & 5,9 \\
\hline$-\mathrm{Mg}$ & 42,6 & 42,0 & 14,3 & 15,2 & 22,2 & 19,6 & 27,0 & 22,0 & 2,0 & 2,0 & 4,7 & 4,1 \\
\hline$-S$ & 42,8 & 38,9 & 18,1 & 15,2 & 16,6 & 18,4 & 27,0 & 23,0 & 3,0 & 3,0 & 1,2 & 1,0 \\
\hline $\mathrm{H}_{2} \mathrm{OD}$ & 0,0 & 0,0 & 0,0 & 0,0 & 0,0 & 0,0 & 0,0 & 0,0 & 0,0 & 0,0 & 0,0 & 0,0 \\
\hline
\end{tabular}

$\mathrm{H}_{2} \mathrm{OD}$, Água deionizada.

Os híbridos submetidos à omissão de $\mathrm{P}$ apresentaram teores foliares de 62,3\% para o N901 e de 73\% para o H9553 inferiores aos teores encontrados no tratamento completo. Com a omissão de P aumentou os teores de $\mathrm{Mg}$ e S em relação a testemunha (Tabela 3). Os teores de $\mathrm{P}$ na parte aérea das mudas com omissão neste nutriente, encontraram-se na faixa adequada que é de 2,5 a $7,5 \mathrm{~g} \mathrm{~kg}^{-1}$, segundo Silva et al. (2000). Porém esses valores mostraram-se insuficientes para o desenvolvimento adequado, ou seja, sem sintomas de deficiência de fósforo, para mudas de tomate industrial.

Os teores apresentados pelas plantas cultivadas em solução completa para o nutriente $\mathrm{K}$ foram inferiores aos descritos como adequados para plantas de tomate por Silva et al. (2000) de $30 \mathrm{a} 50 \mathrm{~g} \mathrm{~kg}^{-1} \mathrm{e} \mathrm{de}$ 20 a $50 \mathrm{~g} \mathrm{~kg}^{-1}$ por Furlani (2004) para plantas. No entanto esses valores, $13,4 \mathrm{~g} \mathrm{~kg}^{-1}$ para o $\mathrm{N} 901$ e de $16 \mathrm{~g} \mathrm{~kg}$ ${ }^{1}$ para o H9553, foram suficientes para produção de mudas sem sintomas de deficiência. A diminuição de 31,3\% N901 e 41,2 \% H9553 no teor de K em relação ao tratamento controle resultou em sintomas de deficiência (Tabela 3).

Sob a omissão de Ca, as mudas dos híbridos de tomate industrial obtiveram teores 85,2\% N901 e 66,7\% H9553 menores em relação ao tratamento completo, sendo o macronutriente que apresentou menor redução no teor foliar entre as omissões em relação à completa, perdendo apenas para o $\mathrm{N}$, que não formou muda. O híbrido N901 proporcionou aumento no teor foliar de Ca com a omissão de $\mathrm{K}$ em relação ao completo (Tabela 3). Este resultado provavelmente está relacionado a ausência do mecanismo de inibição competitiva entre Ca e K favorecendo a absorção de Ca (MALAVOLTA et al., 1997).

A concentração de $\mathrm{Mg}$ foi reduzida em $50 \%$ nas mudas de tomate sob omissão de $\mathrm{Mg}$. Os teores deste nutriente mantiveram-se constantes nas demais omissões. Em solução completa as mudas 
apresentaram 4,0 $\mathrm{g} \mathrm{kg}^{-1} \mathrm{em}$ ambos os híbridos para os teores de $\mathrm{Mg}$ (Tabela 3), valores dentro da faixa de 4 a $6 \mathrm{~g} \mathrm{~kg}^{-1}$ determinada por Silva et al. (2000).

A omissão de S resultou na diminuição do teor deste nutriente nas mudas de 65\% no híbrido N901 e de $74 \%$ no híbrido H9553. A concentração de $\mathrm{S}$ nas folhas aumentou com a omissão individual dos demais (Tabela 3). Malavolta (2006), o teor foliar de fósforo está relacionado com o de enxofre e vice-versa e que a causa dessa interação são as proteínas.

\section{CONCLUSÕES}

A ausência individual dos macronutrientes provocou alterações morfológicas, traduzidas em deficiências nutricionais visíveis em mudas de tomate. Os primeiros sintomas visuais se manifestaram com a omissão de $\mathrm{N}$, água deionizada e $\mathrm{Ca}$, nessa ordem. Os tratamentos com deficiências de $\mathrm{N}$ e Ca foram as que mais afetam as características biométricas altura, diâmetro do caule, número de folhas e matéria seca da parte aérea, das mudas dos híbridos (N901 e H9553) de tomate industrial.

O clorofilômetro pode ser utilizado para avaliar o estado nutricional das mudas de tomate industrial. A carência de $\mathrm{N}$ e de $\mathrm{Mg}$ foram as mais limitantes para o IRC e a omissão de $\mathrm{P}$ e $\mathrm{K}$ não comprometeram, estatisticamente, o IRC nas mudas. Não houve efeitos de interação entre os tratamentos e os híbridos de tomate industrial utilizados.

AGRADECIMENTOS: À Coordenação de Aperfeiçoamento de Pessoal de Nível Superior (Capes) pelo apoio financeiro.

\section{REFERÊNCIAS}

ALVES, A. U.; PRADO, R. M.; GONDIM, A. R. O.; FONSECA I. M.; CECÍLIO FILHO, A. B.. Desenvolvimento e estado nutricional da beterraba em função da omissão de nutrientes. Revista Horticultura Brasileira, Brasília, v.26, n.2, p.292-295, 2008. DOI: https://doi.org/10.1590/S010205362008000200033

BASTOS, A. R. R.; ALVARENGA, M. A. R.; CARVALHO, J. G.; PINHO, P. J.. Nutrição mineral e adubação. In: ALVARENGA M. A. R.. Tomate: Produção em campo, em casa de vegetação e hidroponia. Lavras: Universitária de Lavras, 2013. p.63-120.

BERGMANN, W.. Nutritional disorders of plants: development, visual and analytical diagnosis. Jena: Gustav Fischer, 1992.

CUNHA, A. C. M.; PAIVA, H. N.; XAVIER, A.; OTONI, W. C.. Papel da nutrição mineral na formação de raízes adventícias em plantas lenhosas. Pesquisa Florestal Brasileira, Colombo, n.58, 2009. DOI: http://doi.org/10.4336/2009.pfb.58.35

DOMINGOS, S. F.. Valorização dotomate: Extração supercrítica decompostos bioativos a partir de repiso de tomate. Dissertação (Mestrado em Agronomia) - Instituto Superior de Agronomia, Universidade Técnica de Lisboa, Lisboa, 2009.
EMBRAPA. Empresa Brasileira de Agricultura e Pecuária. Cultivo de Tomate para Industrialização, dez. 2006.

EPSTEIN, E.; BLOOM, A. J.. Mineral nutrition of plants: principles and perspectives. 2 ed. Sunderland: Sinauer Associates, 2005

FAA. Falker Automação Agrícola. Uso do clorofiLOG como ferramenta para recomendação de adubação nitrogenada. Rev. B, Porto Alegre, n.1, p.33, 2008.

FURLANI, A. M. C.. Nutrição Mineral. In: KERBAUY, G. B. Fisiologia Vegetal. Rio de Janeiro: Guanabara Koogan, 2004. p.40-75.

HEWITT E. J.. The effects of mineral deficiencies and excesses on growth and composition. In: ROBINSON J. B. D. Diagnosis of mineral disorders in plants. London: HMSO, 1983. p.54-110.

HOAGLAND, D. R.; ARNO, D. I.. The water-culture method of growing plants without soil. Berkeley: College of Agriculture, University of California, 1950.

MAIA, J. T. L. S.. Cultivo hidropônico do tomateiro do grupo cereja: crescimento, produção e qualidade sob doses de $\mathrm{K}$ e sintomas visuais e anatômicos sob omissão de nutrientes. 
Tese (Doutorado em Fitotecnia) - Universidade Federal de Viçosa, Viçosa, 2012.

MALAVOLTA, E.; VITTI, G. C.; OLIVEIRA, S. A.. Avaliação do estado nutricional das plantas: princípios e aplicações. 2 ed. Piracicaba: Associação Brasileira para a Pesquisa da Potassa e do Fosfato, 1997.

MALAVOLTA, E.. Manual de nutrição mineral de plantas. São Paulo: CERES, 2006.

MINAMI, K.. Produção de mudas de alta qualidade em horticultura. São Paulo: T.A. Queiroz, 1995.

NASCIMENTO, A. R.; FERNANDES, P. M.; BORGES, L. L.; PONTES, N. C.; QUEZADO-DUVAL, A. M.. Controle químico da mancha bacteriana em mudas de tomate para processamento industrial. Bioscience Journal, Uberlândia, v.29, n.6, p.1878-1886, 2013. DOI:

https://doi.org/10.1590/S0102-05362013000100003

OVIEDO, V. R. S.; MINAMI, K.. Producción de tomate tipo italiano en función del volumen de la celda y de la edad de las mudas. Bragantia, Campinas, v.71, n.3, p.21-27, 2012. DOI: http://dx.doi.org/10.1590/S000687052012000100004

RAMOS, M. J. M.; MONNERAT, P. H.; PINHO, L. G. R.. Leitura SPAD em abacaxizeiro imperial cultivado em deficiência de macronutrientes e de boro. Revista Brasileira de Fruticultura, Jaboticabal, v.35, n.1, p.277-287, 2013. DOI: https://doi.org/10.1590/S0100-29452013000100032
RAIJ, B. V.. Fertilidade do solo e adubação. Piracicaba: POTAFOS, 1991.

SILVA, F. A. S.; AZEVEDO, C. A. V.. Principal Components Analysis in the Software Assistat-Statistical Attendance. In: WORLD CONGRESS ON COMPUTERS IN AGRICULTURE, 7. Anais. Reno: American Society of Agricultural and Biological Engineers, 2009.

SILVA, J. B. C.; GIORDANO, L. B.. Produção mundial e nacional. In: SILVA, J. B. C.; GIORDANO, L. B.. Tomate para processamento industrial. Brasília: EMBRAPA, 2000. p.37-59.

TAIZ, L.; ZEIGER, E.. Fisiologia vegetal. 4 ed. Porto Alegre: Artmed, 2009.

VIÉGAS I. J. M.; SOUSA G. O.; SILVA A. F.; CARVALHO J. G.; LIMA M. M.. Composição mineral e sintomas visuais de deficiências de nutrientes em plantas de pimenta-longa (Piper hispidinervum C. DC.). Revista Acta Amazônica, Manaus, v.43, n.1, p43-45, 2013. DOI: http://dx.doi.org/10.1590/S0044-59672013000100006

WPTC. The World Processing Tomato Council. World production estimate of tomatoes for processing. Monteux, 2020.

ZOTARELLI, L.; CARDOSO, E. G.; PICCININ, J. L.; URQUIAGA, S.; BODDEY, R. M.; TORRES, E.; ALVES, B. J. R.. Calibração do medidor de clorofila Minolta SPAD-502 para o uso na cultura do milho. Seropédica: Embrapa Agrobiologia, 2002.

A CBPC - Companhia Brasileira de Produção Científica (CNPJ: 11.221.422/0001-03) detém os direitos materiais desta publicação. Os direitos referem-se à publicação do trabalho em qualquer parte do mundo, incluindo os direitos às renovações, expansões e disseminações da contribuição, bem como outros direitos subsidiários. Todos os trabalhos publicados eletronicamente poderão posteriormente ser publicados em coletâneas impressas sob coordenação da Sustenere Publishing, da Companhia Brasileira de Produção Científica e seus parceiros autorizados. Os (as) autores (as) preservam os direitos autorais, mas não têm permissão para a publicação da contribuição em outro meio, impresso ou digital, em português ou em tradução. 